\title{
A Referenciação em textos de alunos de cursinho pré-vestibular
}

Elisângela Lima Vagula**** Aline Emilio

\begin{abstract}
Resumo: Este artigo tem como objetivo apresentar um estudo sobre a referenciação em textos de alunos de cursinho pré-vestibular. Tendo em vista que a referência é um dos fatores importantes na progressão textual, optamos por analisar textos de alunos de cursinho por acreditarmos que tais textos podem nos oferecer condições favoráveis de análise, uma vez que esses alunos já passaram por várias etapas do processo de escolarização e se preparam para o vestibular. Recorremos a autores que tratam dos conceitos de texto e discurso, tendo em vista que nosso olhar recai sobre a construção do texto, por meio do processo de referenciação. Primeiramente, faremos um aclaramento sobre os conceitos de texto e discurso e, em seguida, passaremos à referenciação. Buscaremos apoio em autores que se dedicam à linguística textual, dando ênfase aos estudos de Koch (1997, 2002), os quais oferecem embasamento para análise dos textos que fazem parte deste trabalho.

Palavras-chave: Texto-discurso; Referenciação; Análise.

Abstract. This article presents a study about referencing in texts written by students taking a preparatory course for the university entrance exam called vestibular. Considering that referencing is an important factor in textual progression, the analysis concentrated on texts written by students who have passed through several stages of schooling. The literature review included the concepts of text and discourse. The study is supported by authors who study text linguistics whereas Koch's studies (1997 and 2002) are emphasized as they provide the basis to analyze the texts collected for this research. Keywords. Text-discourse; Referencing process; Analysis.
\end{abstract}

\section{Introdução}

Neste estudo, propomo-nos a analisar textos de alunos de cursinho pré- vestibular a fim de verificar as estratégias e escolhas lexicais pelas quais se constrói a referência no texto. A análise permitirá verificar os meios, os recursos de que se utilizam os locutores para tecer o texto com coesão e coerência.

Para esta análise, buscamos respaldo em autores que tratam dos conceitos de texto e discurso, em sua maioria na perspectiva da linguística textual. Privilegiamos, no entanto, estudos de Ingedore Villaça Koch, que nos oferecem conceitos voltados para o foco de nossa pesquisa, a referenciação.

\footnotetext{
Professora especialista pela Universidade Estadual de Ponta Grossa (UEPG). E-mail: limavagula@ bol.com.br

Professora doutora. Universidade Federal de Santa Catarina (UFSC). E-mail: alinemilio@uol.com.br 
Uma vez que nosso material de pesquisa sobre a construção da referência se compõe de textos, discutiremos, primeiramente, o conceito de texto e o que o difere ou o aproxima do conceito de discurso.

De acordo com Koch (2002), o sentido no texto é constituído na interação texto-sujeito (ou texto coenunciadores), e não em algo que preexista a essa interação.

Estudos atuais sustentam a ideia de que tanto o discurso como o texto têm como base a interação dos sujeitos, que, com o ato da enunciação, visam à concretização de finalidades. Assim, ao se tratar de discurso, é importante também que sejam considerados os aspectos sociais, históricos e culturais.

Considerando que há certa tendência a se empregar texto por discurso, é necessária uma revisão e reflexão sobre essa questão, pois a compreensão sobre o conceito desses termos permite um melhor posicionamento quanto à análise da construção da referência em textos de alunos.

Koch (2002) afirma que a referência não é simples representação extensional de referente do mundo extramental; é, sim, uma realidade construída, mantida e alterada não somente pela forma com que se nomeia o mundo, mas, acima de tudo, pela forma com que se pode interagir sociocognitivamente com ele.

Tal afirmação deixa claro que ao tomarmos um referente para o discurso não o vemos como um objeto representacional do mundo, mas sim como um referente constituído sociocognitivamente. Desse modo, estamos tratando de objetos de discurso e não de objetos de mundo.

Como se verá na sequência, essa perspectiva será um dos pontos que irão orientar nossa análise e portanto passaremos a tratar dos conceitos de texto e discurso, referência e referenciação, e, por fim, apresentaremos as análises dos textos selecionados.

\section{Texto e Discurso}

Não é simples definir o que é texto, discurso, e situar a referenciação. Por isso, procuramos primeiramente examinar conceitos de texto e discurso para só então verificar o papel da referenciação. Vale ainda salientar que não pretendemos aqui esgotar o assunto em torno de tais conceitos, pois sabemos que eles dão margem a muitas reflexões - nosso estudo se limita ao interesse para a análise dos textos neste trabalho. 
Travaglia (1996) define discurso como toda atividade comunicativa de um locutor, em uma situação de comunicação determinada, e refere-se ao texto como o produto concreto dessa atividade comunicativa, que se faz seguindo regras e princípios discursivos sócio-historicamente estabelecidos.

De acordo com Koch (1997), texto pode ser concebido como resultado parcial de nossa atividade comunicativa, que compreende processos, operações e estratégias que têm lugar na mente humana e são postos em ação em situações concretas de interação social.

Ao examinarmos tais autores, evidenciamos que para ambos o texto é resultado da atividade comunicativa que desempenhamos no dia a dia. Emitimos palavras, por meio das quais se constrói o texto coeso e coerente, garantindo o sentido necessário para que o interlocutor possa estabelecer relações ao que é proferido, de modo que recaia na compreensão mútua e assim progrida o discurso.

Ao interagir, os interlocutores valem-se de estratégias e operações mentais necessárias para que a comunicação seja constituída de sentido, e é nessa relação que o texto se concretiza.

É possível fazer uma diferenciação entre texto e discurso na perspectiva de que discurso é a atividade comunicativa e texto é resultado dessa atividade e requer, como já mencionamos, operações e estratégias mentais, em dada situação de interação.

É comum encontrarmos autores que tratem texto e discurso como sinônimos. Costa Val (1999) define tais termos como ocorrência linguística falada ou escrita, de qualquer extensão, dotada de unidade sociocomunicativa, semântica e formal, sem fazer qualquer distinção entre um e outro.

Este levantamento mostra que não é difícil entender o uso desses termos como sinônimos se considerarmos a linha tênue que os separa. $\mathrm{Na}$ prática, o texto e o discurso ocorrem simultaneamente, sem que nos demos conta da atividade complexa que desenvolvemos diariamente. Muitas definições de texto e de discurso se entrelaçam, como podemos verificar na reflexão dos autores.

Lançamos mão ao trabalho de Cardoso (1999), como forma de melhor entender a questão. A autora afirma que texto é a manifestação verbal do discurso, e que um discurso é normalmente constituído de uma pluralidade de textos. Assim, um texto é atravessado por vários discursos, em sua singularidade. 
Das teorias apresentadas, concluímos que o discurso só tem vida no texto. Ambos se constituem por meio de sujeitos que interagem em dada situação. No entanto, tais sujeitos dispõem de estratégias cognitivas que permitem a compreensão de seu coenunciador.

Após essa breve tentativa de estabelecer a diferença entre texto e discurso, percebemos que, neste trabalho, não deveremos tratá-los como sinônimos, mas considerarmos apenas o texto, uma vez que o objetivo é verificar estratégias de referenciação utilizadas pelos alunos em textos escritos resultantes de produção em sala de aula.

Antes de entrarmos na questão da referência e da referenciação, delinearemos alguns comentários sobre coesão e coerência, uma vez que fizemos menção a esses elementos imprescindíveis para a construção do sentido no texto.

\section{Coesão e Coerência}

Para tratar da questão da coesão e da coerência, voltamos a Koch (1997), para quem a coesão ocorre por meio de elementos linguísticos presentes na superfície textual, que se interligam formando sequências de sentido. A autora cita duas modalidades de coesão: a remissão, que desencadeia a reativação de referentes por meio da referenciação anafórica ou catafórica, e a sequênciação, que faz o texto avançar sem comprometer sua continuidade de sentidos.

A partir dessa afirmação, podemos considerar que os elementos constituintes da superfície textual dependem do processo de referenciação, o qual ocorre por meio da remissão que irá ativar ou reativar determinado referente, garantindo a continuidade do texto.

Para a autora, a coerência não está no texto, mas é construída a partir dele, em uma situação de interação em que se consideram alguns fatores de ordem cognitiva, situacional, sociocultural e interacional. E nessa perspectiva os recursos coesivos presentes na superfície textual servem de pistas para orientar o interlocutor na construção do sentido. A autora afirma ainda que nas relações entre os elementos que permitem a coerência é necessário, muitas vezes, recorrer a estratégias interpretativas, como as inferências e as estratégias de negociação de sentido. 
A referenciação em textos de alunos de cursinho pré-vestibular

Ao relacionarmos a coerência a estratégias interpretativas e a estratégias de negociação de sentido, verificamos que os sujeitos constroem o sentido no texto por meio da atividade discursiva, por Koch (2002) denominada referenciação, a qual possibilita a ativação ou a reativação de referentes que delineiam, moldam, dão forma ao discurso.

Isso tudo, nos leva a compreender que a referenciação como processo cognitivo é um dos fatores responsáveis pela coesão e a coerência do texto, permitindo ao locutor reativar o referente para dar sequência significativa ao texto.

\section{Referência e Referenciação}

Assim como em texto e discurso, os termos referência e referenciação também recebem de alguns autores a mesma definição. Por esse motivo, faremos uma breve revisão a fim de elucidar os conceitos.

Para Marcuschi (2000), a referência é uma atividade discursiva em que os referentes passam a ser objetos de discurso. Declara, ainda, que a referência equivale a um falar de sem a preocupação com a verdade e a existência. $\mathrm{Na}$ sua opinião, a discretização do mundo empírico (extra-mente) não é um dado apriórico, mas uma elaboração sociocognitiva.

Já uma distinção entre referência e referenciação pode ser encontrada em Koch (2002), uma vez que ela considera a referência como o resultado da operação que realizamos quando, para designar, representar ou sugerir algo, usamos um termo ou criamos uma situação discursiva referencial com essa finalidade. Quanto à referenciação, a autora considera-a uma atividade discursiva.

Além disso, a referência não é entendida como simples representação de referentes do mundo extra-mental, mas uma realidade construída, mantida e alterada não somente pela forma como se nomeia o mundo, mas, acima de tudo, pela forma como sociocognitivamente se interage com ele.

Podemos notar que Marcuschi o termo referência designa a atividade conversacional, enquanto Koch emprega essa mesma designação para o termo referenciação, pois para ela a referência é o resultado da atividade conversacional. 
Consideramos relevante a posição de Koch, uma vez que fica claramente estabelecido um processo e um consequente resultado. Em outras palavras, é por meio da referenciação que se constrói a referência.

De acordo com Koch e Marcuschi (1998), a progressão referencial se dá com base em uma complexa relação - entre linguagem, mundo e pensamento - centralizada no discurso. Essa relação permite que os referentes não sejam tomados como entidades apriorísticas, mas como objetos de discurso.

Entendemos, portanto, que não se trata de criar um mundo desvinculado do real, ou simplesmente inventado, mas um mundo de representações construídas a partir da realidade que é compartilhada por indivíduos aí inseridos; o indivíduo atua sobre o real de forma representacional, mediado pela mente, que é parte essencial de todo esse processo de captação da realidade. E é nessa perspectiva que os objetos de discurso não têm ligação direta com os objetos de mundo.

Para designar os referentes, entendidos aqui como objetos de discurso, é importante retomar Koch (1997) quando afirma que a remissão desencadeia a reativação de referentes por meio da referenciação anafórica ou catafórica. Segundo a autora, a remissão para a frente, denominada catáfora, realiza-se preferencialmente por meio de pronomes demonstrativos ou indefinidos neutros (isto, isso, aquilo, tudo, nada), ou de nomes genéricos, mas também por meio das demais espécies de pronomes, numerais e advérbios pronominais.

Em relação à anáfora, Marcuschi (2005) afirma que ela é usada para designar expressões que, no texto, reportam-se a outras expressões, enunciados, conteúdos ou contextos textuais (retomando-os ou não), contribuindo para a continuidade tópica e referencial.

A anáfora direta retoma referentes previamente introduzidos, estabelecendo uma relação de correferência entre os elementos anafóricos e seu antecedente. Na anáfora indireta, não ocorre uma retomada de referentes, mas sim uma ativação de novos referentes e há uma ancoragem no universo textual, segundo esse mesmo autor.

Na visão de Koch (2002), as anáforas indiretas são responsáveis pelos processos de ativação e reativação referencial, fundamentais à progressão do texto. A autora afirma ainda que as anáforas indiretas se caracterizam pelo fato 
de não existir no cotexto ${ }^{1}$ um antecedente explícito, mas sim um elemento de relação, que pode ser denominado âncora e é decisivo para a interpretação.

Em relação ao exposto, podemos dizer que a ativação e a reativação anafóricas ocorrem por meio da referenciação, ou seja, por meio do processo de referenciação se designa o referente que propiciará a progressão referencial.

Entendemos que a anáfora direta é responsável pela retomada de elementos já introduzidos, enquanto a indireta traz novos dados e, mesmo não apresentando um antecedente explícito, mantém relação com os elementos antecedentes.

Outro aspecto interessante é que a progressão textual também pode se realizar por meio de atividades formulativas, caso em que o locutor opta por introduzir no texto recorrências de variados tipos, e destaca a reiteração de itens lexicais: o paralelismo, as paráfrases, a recorrência de elementos fonológicos e de tempos verbais, acrescenta Koch.

A partir da reflexão sobre referenciação, referência e referente, entendemos que a referenciação é necessária para a existência do discurso; é, pois, por meio da referenciação que se mobilizam os elementos designadores a fim de dar sequência coesiva ao texto. Por meio da referenciação, pode-se remeter ao referente, contribuindo para a construção da referência e para a efetivação da coerência na ação comunicativa.

Além disso, a referenciação se faz em uma relação mediada pelos referentes que se desenvolvem no discurso, sem uma relação direta com os objetos de mundo. Esses referentes são constituídos discursivamente e tomam a forma de objetos de discurso em dada ação de comunicação, considerando fatores sociocognitivos, históricos e culturais que interferem na interação realizada pelos interlocutores. Essa interação resulta na construção da referência e no sentido do texto.

Nessa perspectiva, o estudo de referenciação propiciará a nossa análise uma visão ampla, pois o que vem associado a tal processo permite considerar fatores que vão além de verificar questões linguísticas superficiais no texto. Assim, poderemos observar a maneira como o aluno constrói o texto, valendose do referente para a construção da referência.

\footnotetext{
'"São as sequências verbais encontradas antes ou depois da unidade a interpretar." (MAINGUENEAU, 2001, p. 27) 
Tendo em vista que pretendemos verificar os mecanismos, as formas como o aluno de cursinho pré-vestibular - considerado como enunciador, que já acumulou subsídios para construir adequadamente a referenciação — ativa e reativa o referente por meio do processo de referenciação, que constrói a referência e dá progressão ao texto, tomaremos como embasamento teórico as reflexões em torno de texto e discurso e referenciação e referência porque nos oferecem o suporte necessário à identificação do processo de referenciação realizado pelo aluno no momento de produção.

Assim, analisaremos a ocorrência dos elementos anafóricos e catafóricos e o modo como as escolhas dos recursos lexicais e gramaticais são introduzidos ou retomados no texto a fim de construir a referência e desencadear a progressão textual.

\section{Análise da Referenciação: textos de cursinho pré-vestibular}

Os textos analisados foram disponibilizados por uma professora de cursinho pré-vestibular da cidade de Ponta Grossa. São narrativas que apresentam temáticas diferenciadas. Selecionamos apenas dois textos, os quais oferecem recursos linguístico-discursivos para a nossa proposta de análise.

Sabemos que a referência não é propriedade exclusiva dos itens lexicais, mas da atividade de interação que engloba cultura, crenças, língua e contextos, os quais devem ser comuns para que se possa com eles referir. É por meio das escolhas lexicais que o locutor ativa referentes que possibilitam ao interlocutor estabelecer relações e interpretar o que é referido.

Desse modo, procuraremos destacar nos textos como o aluno-autor utiliza os recursos que promovem a coesão e a coerência e de que modo ele sinaliza esses recursos. Mais especificamente, verificaremos como o aluno-autor se refere e reativa referentes por meio do processo de referenciação, construindo a referência e o sentido do texto.

Vale observar que a fidedignidade permeou a transcrição dos textos. Também queremos registrar que somente solicitamos à professora que nos cedesse textos dos alunos. Assim, ela nos forneceu narrativas para a análise. 


\section{Texto 1}

\begin{tabular}{|l|c|}
\hline 1 & Acerto de contas \\
2 & Hoje cheguei do trabalho e tive uma surpresa. Ao abrir a \\
3 & porta, encontro Marcela sentada no sofá a minha espera. Mal entro \\
4 & e ela me interpela: \\
5 & - Temos que acertar umas contas! Muito assustada, larguei \\
6 & minha bolsa e disse: \\
7 & - Mas o que está acontecendo? Não estou entendendo nada! \\
8 & Marcela ainda inconformada secou minhas lágrimas, res- \\
9 & pirou fundo, me olhou firmemente e explicou: \\
10 & me pedia sempre pra falar a verdade? Liguei hoje para o veterinário \\
11 & e ele disse que Nick não aguentou e morreu, por que mentiu? Muito \\
12 & envergonhada tentei explicar: \\
13 & - Minha filha perdoe-me por não te falar a verdade, já tinha \\
14 & até comprado outra gata! Você ainda é tão pequena, tem apenas cin- \\
15 & co anos, queria poupá-la da tristeza, mas prometo que isso não vai \\
16 & mais acontecer! \\
17 & Dei-a um abraço e diante da situação aprendi, forçosamente, \\
18 & a enxergar a sinceridade de uma criança. \\
19 & Ah! Que bom seria poder resolver meus problemas assim, com pala- \\
20 & vras sinceras de uma criança. \\
\hline
\end{tabular}

A temática do texto é a infância. $\mathrm{O}$ aluno-autor cria uma narrativa em que o episódio é o conflito entre mãe e filha. A mãe se situa como narradora-personagem, razão pela qual o Acerto de contas é predominantemente narrado em primeira pessoa.

Para construir a referência, o aluno-autor recorre a uma situação de conflito em que a mãe, tentando esconder um fato que, acreditava ela, poderia ferir sua filha, acaba por cometer um erro ao agir dessa forma. A mãe recebe uma lição de moral da criança. O conflito que gera o Acerto de contas acaba por ser a referência principal do texto.

O fato de a mãe ser a narradora-personagem colabora para a elaboração do suspense na história, pois ela narra o fato do seu ponto de vista, e a omissão de revelar esse fato no início do texto faz com que o leitor-interlocutor 
acompanhe toda a sua angústia, até o momento em que a filha esclarece o motivo de seu descontentamento. O suspense que se cria nos dois primeiros parágrafos ocorre por meio de expressões que deixam lacunas, mas oferecem pistas - que podem ser inferidas pelo leitor-interlocutor - de que se trata de um problema da filha com a mãe. Como podemos observar:

$$
\begin{aligned}
& \text { [...] encontro Marcela sentada no sofá a minha espera.” (linha 2) } \\
& \text { - Temos que acertar umas contas.” (linha 4) }
\end{aligned}
$$

A última expressão reforça a referência a um episódio de conflito e remete anaforicamente ao título.

A construção do texto, por meio de pistas, leva o leitor-interlocutor a inferir, antes de ser mencionado, que Marcela é filha, na narrativa; isso, porém, só é explicitado no texto por meio de uma anáfora indireta - "Minha filha" (linha 13) - que remete a "Marcela" (linhas 2 e 7), confirmando-se assim a hipótese do leitor. De acordo com Marcuschi (2005), a anáfora indireta é um caso de referência textual, de indução ou ativação de referente no processo textualdiscursivo, que envolve atenção cognitiva conjunta dos interlocutores.

Quando a narradora-personagem diz "-Mas o que está acontecendo? Não estou entendendo nada!” (linha 6), ela traduz a mesma sensação provocada no leitor-interlocutor: a de não estar entendendo o que acontece.

Apesar de se apresentarem apenas pistas sobre o que ocorrerá adiante, esse início é coerente, porque seguimos a linha de raciocínio que é proposta pelo aluno-autor, e vale aqui parafrasear Koch (1997): a coerência não está no texto, mas é construída a partir dele.

O impasse começa a ser resolvido nas linhas (10 e 11): "Liguei hoje para o veterinário e ele disse que Nick não aguentou e morreu, por que mentiu?"

Com essa informação, o leitor-interlocutor imediatamente inferirá que se trata de um animal de estimação, pois ao se mencionarem os itens lexicais veterinário, Nick e morreu se constitui uma situação por meio das escolhas lexicais, levando o leitor-interlocutor a recorrer ao que Koch (2002) denomina modelos, que são os conjuntos de conhecimentos socioculturalmente determinados e vivencialmente adquiridos que permitem o entendimento do que não está explícito.

O aluno-autor procura ainda manter a omissão sobre qual seja 0 animal até as linhas 13 e 14, quando a personagem-mãe declara que "Já tinha 
até comprado outra gata!" E podemos observar, nesse trecho, que o item lexical gata (linha 14) substitui Nick (linha 11). Ao mencionar o nome, cria-se antecipadamente um efeito de indefinição sobre o animal, o que estimula a curiosidade do leitor-interlocutor em descobrir que animal é Nick.

A fim de evitar a repetição e dar progressão ao texto, podemos ainda observar a ocorrência significativa do recurso coesivo da elipse, ou referência elíptica, nas falas da narradora-personagem:

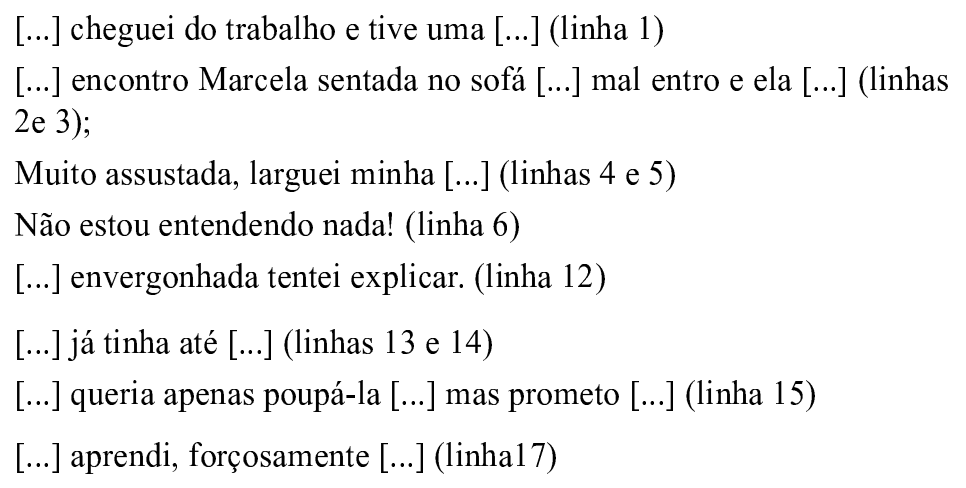

Ao referir Marcela, esse recurso também é utilizado nas linhas 7 e 8: "[...] inconformada, secou minhas lágrimas, respirou [...] me olhou [...] e explicou".

Outro recurso que destacamos é a anáfora pronominal isso (linha 15), que remete ao que foi expresso na linha 9, "mentiras" e, na linha 11, "mentiu?"

Em “ela" (linha 3), "você" (linha 14), "poupá-la” (linha 15) e "dei- $a$ " (linha 17), ocorre remissão anafórica por meio de pronomes que reativam o referente Marcela (linha 2) e na linha 19 a anáfora pronominal meus corresponde à primeira pessoa, tratando-se, portanto, de uma remissão à narradorapersonagem.

Esses recursos vão ligando os elementos uns aos outros ao mesmo tempo que os retoma e, assim, por meio da costura do texto se dá a construção do sentido.

Ao relacionar as falas de Marcela com a idade descrita - "cinco anos" -, ocorre incoerência, pois as atitudes da garotinha não condizem com atitudes de criança de cinco anos, como podemos verificar: 
- Temos que acertar umas contas! (linha 4)

- Não era você que dizia que não suportava mentiras, que me pedia sempre pra falar a verdade? Liguei hoje para o veterinário e ele disse que Nick não aguentou e morreu, por que mentiu? (linhas 9 a 11)

Para tratar de um assunto dessa maneira se necessita de um grau de abstração que, provavelmente, a criança de cinco anos ainda não desenvolveu.

Na conclusão da mãe diante da situação (“[...] aprendi, forçosamente, a enxergar a sinceridade de uma criança." - linhas 17 e 18), fica evidenciado que o aluno-autor coloca a personagem-narradora em situação de lição de moral, pois a mãe aprendeu a enxergar a sinceridade de uma criança. Essa situação serviu também para o aluno-autor expressar o resultado sobre a referência que pretendeu construir sobre a infância. Ao fazer uso da descrição indefinida uma criança, refere-se não a Marcela, mas a crianças de modo geral. Entendemos, desse modo, que a expressão nominal $a$ sinceridade remete implicitamente à lição de moral gerada pela referência ao episódio Acerto de contas.

\section{Texto 2}

\begin{tabular}{|c|c|}
\hline $\begin{array}{l}1 \\
1 \\
2 \\
2 \\
2 \\
2 \\
2 \\
2\end{array}$ & 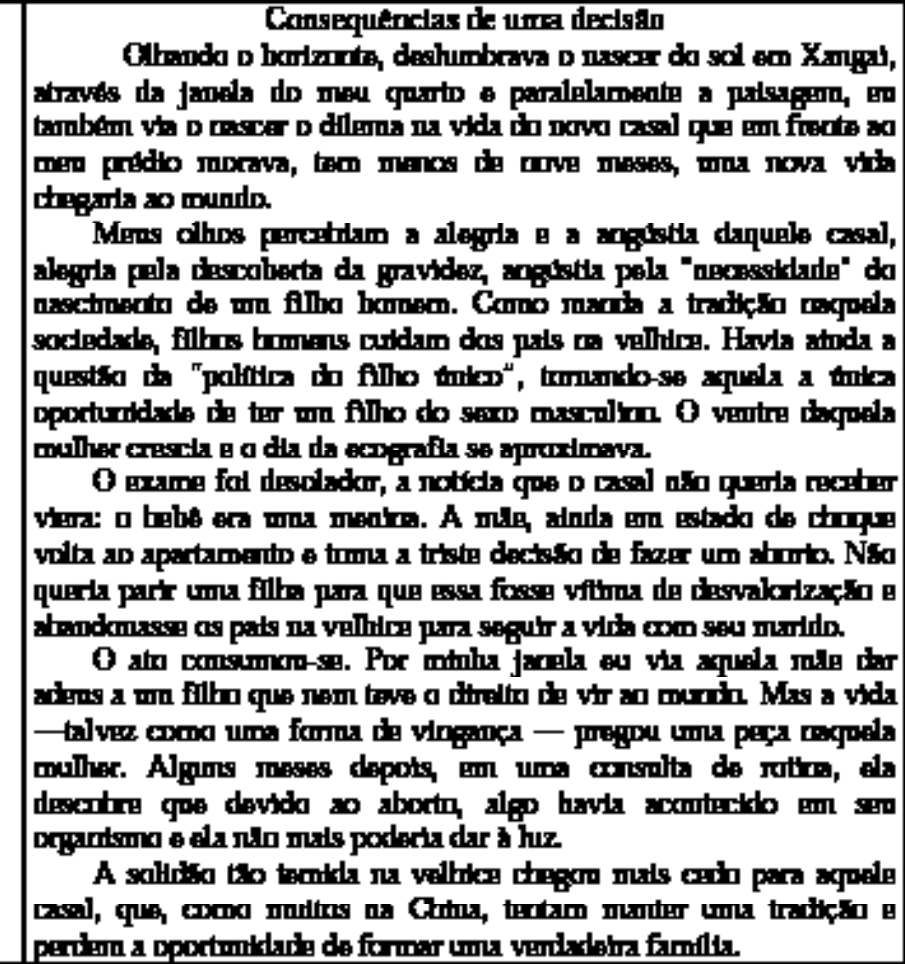 \\
\hline
\end{tabular}


A proposta para a produção desse texto tem como tema "paisagem vista da minha janela". Claro está que o autor emprega o substantivo paisagem revestido de um sentido figurado, pois o que o narrador observa, de sua janela, é uma situação de conflito. Essa observação desencadeia o relato.

Através da referência gravidez e das relações construídas no texto pelo aluno-autor, percebemos que sua intenção é produzir uma narrativa que, ao final, abra espaço para a crítica sobre uma tradição chinesa, o que fica evidente nas linhas 25 e 26: "[...] como muitos na China, tentam manter uma tradição, e perdem a oportunidade de formar uma verdadeira família."

O aluno-autor produziu uma narrativa ficcional a fim de tratar de uma questão real e, para isso, cria uma referência de homem e mulher que remete àqueles chineses que seguem tal tradição. Com a utilização de muitos (linha 25), o aluno-autor protege o todo, referindo-se apenas aos chineses que procuram manter uma tradição. Esse apego à tradição acarreta, muitas vezes, a perda de uma oportunidade de constituir uma verdadeira família.

Consequências de uma decisão é uma história que versa sobre um fato observado pelo narrador na cidade de Xangai (linha 1).

Para que o interlocutor possa fazer inferências, o aluno-autor inicialmente fornece pistas. A primeira está na descrição definida como "o dilema" (linha 3), que anuncia uma dificuldade encontrada pelo casal diante de uma situação. Entretanto, ainda não é possível saber qual é o problema, o qual só será esclarecido pelo enunciado "alegria pela descoberta da gravidez, angústia pela necessidade do nascimento de um filho homem" (linhas 7 e 8).

Além da expressão "o dilema", destacamos no primeiro parágrafo "uma nova vida" (linha 4), que faz remissão catafórica ao termo gravidez (linha 7), encaminhando à expressão "consequências de uma decisão", no título.

No terceiro parágrafo, o paradoxo "a alegria e a angústia" (linha 6) se dissolve ao fazer remissão catafórica à expressão referencial "o bebê era uma menina" (linha14), e revela-se também o referente de notícia (linha 13) por remissão anafórica. O que permanece é a "angústia"; e o referente de decisão, item lexical utilizado no título, constitui-se cataforicamente, na linha 15, por meio da expressão "toma a triste decisão de fazer o aborto".

Podemos considerar ainda essa expressão da linha 15 e "ela não mais poderia dar à luz" (linha 23) como referenciais anafóricos de "consequências de uma decisão", expressão que constitui o título. 
Como forma de progredir o texto, o aluno-autor faz algumas escolhas que colaboram para a construção do referente: "um filho homem" (linha 8), por exemplo, é substituído por "um filho do sexo masculino" (linha 11), como forma de remissão diferenciada ao referente.

Podemos observar a referenciação pela utilização de itens lexicais do mesmo campo semântico: ventre (linha 11), bebê (linha 14), aborto (linha 15), parir (linha 16), dar à luz (linha 23) como marcas que contribuem para a coesão do texto, já que esses itens estão associados ao referente gravidez.

A nominalização "o ato" (linha 18) faz remissão anafórica a "fazer um aborto" (linha 15), revelando que o uso de uma expressão definida denota a qualidade, ou a propriedade que o produtor quis destacar, conforme os propósitos a serem atingidos em dada situação de interação, conforme orienta Koch (1997).

Em "novo casal" (linha 3), "daquele casal" (linha 6), "o casal" (linha 13), "aquele casal" (linhas 24 e 25), temos expressões que podem trazer um acréscimo de sentido ao reiterar o item lexical, casal, de acordo com Koch (2002).

Em relação aos termos que acompanham esse item, podemos dizer que novo é um qualificador que orienta o leitor-interlocutor a criar uma imagem de um casal jovem, o que pode ser confirmado pela relação que se estabelece na linha 24: "A solidão tão temida na velhice chegou mais cedo para aquele casal". Acerca de daquele pode-se dizer que mostra um distanciamento do casal em relação ao narrador-observador. No caso do emprego do determinante $o$, percebe-se uma proximidade do narrador com os conflitos do casal. E, novamente, o distanciamento, por meio do uso do pronome demonstrativo aquele.

Podemos ainda destacar que o item casal, acompanhado do artigo definido $o$ e do pronome demonstrativo aquele, nas expressões: "o casal", "daquele casal" e "aquele casal", constituem o que Koch (1997) denomina expressões nominais definidas.

O conflito que emana da tomada de decisão sobre o que fazer com a gravidez está focado da linha 14 até a 23. Vale lembrar que, nesse momento tão decisivo, não há menção ao pai e o referente mãe é retomado por elipses:

$[\ldots]$ volta ao apartamento [...] toma a triste decisão [...] (linha 15)

Não queria parir [...] (linhas 15 e 16). 
Retomamos aqui, acerca de quando o aluno-autor reitera o item lexical mãe, o que afirma Koch (1997) sobre o acréscimo de sentido: "a mãe" (linha 14), "aquela mãe" (linha 18). O emprego de "aquela mãe" (linha18) remete à expressão "a mãe" (linha 14), de modo que o pronome demonstrativo aquela intensifica o sofrimento da mãe que o narrador-observador acompanhou de perto nas linhas 14 e 15: "a mãe, ainda em estado de choque volta ao apartamento e toma a triste decisão de fazer um aborto", ou seja, remete à mãe e a todo o seu sofrimento. Já na expressão definida "naquela mulher" (linhas 20 e 21), que também remete à expressão "a mãe", o pronome demonstrativo é utilizado como indicativo de afastamento do narrador-observador, e reforçado pela utilização do referente mulher.

\subsection{Sobre a Análise}

Por meio dos textos narrativos dos alunos, com temáticas diferenciadas, pudemos realizar as constatações a que nos propusemos, verificando como se dá o processo de referenciação que garante a progressão textual.

Considerando que são textos produzidos no ambiente escolar, com finalidade de preparação para o vestibular, constatamos que foram postos à disposição dos alunos alguns textos de apoio temático, a fim de subsidiá-los no desenvolvimento do conteúdo, que serviria de base para a narração.

Essa preparação contribuiu, como investimento, para a ampliação do conhecimento do aluno e colaborou para a construção dos modelos de que trata Koch (2002). Portanto, esse embasamento possibilitou ao aluno estabelecer novas relações cognitivas que enriqueceram a produção textual.

Verificamos que os referentes foram construídos, principalmente, a partir das relações que se estabeleceram no texto, por meio de anáforas, catáforas, elipses, reiterações e associações de itens lexicais de um mesmo campo semântico.

Dentre esses recursos que garantem a coesão e a coerência no texto, observamos que os mais utilizados foram as anáforas pronominais, que reativam os referentes presentes no texto, e as elipses, que estão entre os elementos que permitem a organização básica do texto, estabelecendo uma ordenação entre os segmentos textuais.

Observamos também a utilização de anáforas indiretas, que apresentam elementos de um mesmo campo lexical, mantendo relação com o referente principal por associação. 
Nos dois textos, pelo modo como a referência vai se construindo, pelo processo de referenciação, é possível perceber uma certa habilidade dos alunos ao fazerem uso de tais estratégias sociocognitivas, capazes de garantir o sentido no texto. E não se pode deixar de registrar que os alunos-autores contam, também, com o conhecimento compartilhado pelos interlocutores, o que contribui para a formação das concepções em torno de assuntos socialmente constituídos.

\section{Considerações Finais}

Nossa reflexão em torno de texto e discurso nos levou a compreender que são muitos os fatores que devem ser considerados para a constituição de um texto, entre eles os socioculturais, os históricos e os sociocognitivos. Destacamos o aspecto sociocognitivo, responsável pela referenciação que os interlocutores são capazes de realizar no ato da enunciação, mostrando que a relação interlocutores é fundamental para a construção da referência e, consequentemente, para a construção do texto.

Nas análises, de acordo com as reflexões teóricas, verificamos que as representações do mundo são negociadas no interior do discurso, deixando de ser objetos de mundo e passando a ser objetos de discurso. Os alunos-autores construíram seus textos a partir de referentes que fazem parte do universo textual constituído por suas experiências de mundo. Assim, ao referir, o sujeito não remete a um objeto real, mas a objetos constituídos discursivamente, aos quais os interlocutores recorrem no momento da enunciação.

Percebemos que, no momento da interação, o interlocutor recorre também a esse universo textual para remeter ao referente que é solicitado, porém suas representações poderão não ser exatamente as mesmas do produtor, pois cada indivíduo as constitui de acordo com suas experiências. Isso evidencia a necessidade do conhecimento compartilhado.

Observamos também que, de modo geral, os alunos-autores procuraram estabelecer relações entre os referentes designados para constituir os textos, ora utilizando anáforas pronominais, associativas, ora empregando elipses, ora reiterando elementos de importância para o texto, além de outras estratégias, por meio das quais puderam, ao mesmo tempo, dar sentido ao texto e construir uma história que fosse interessante ao leitor-interlocutor.

E, para dar sequência ao texto, fizeram remissões a referentes que foram ativados e reativados de modo à progressão seguiu de maneira coesa 
e coerente, garantido a manutenção do tópico referencial e a construção do sentido no texto.

Por tudo isso, podemos dizer que os alunos já ensaiam formas de referenciar, por meio das estratégias citadas pelos estudiosos. Nem sempre os textos apresentaram plena coesão e coerência, mas entendemos que esses alunos já dominam um uso linguístico-discursivo referencial capaz de evidenciar que o objeto de discurso se produz, de fato, no ato interativo.

\section{Referências}

CARDOSO, S. H. B. Discurso e ensino. Belo Horizonte: Autêntica, 1999.

A questão da referência. Campinas: Autores Associados, 2003.

COSTA VAL, M. G. Redação e textualidade. 2 ed. São Paulo: Martins Fontes, 1999.

Repensando a textualidade. In: AZEVEDO, J. C. de (Org.). Língua portuguesa em debate: Conhecimento e ensino. Petrópolis: Vozes, 2000.

EMILIO, A. A expressividade na arquitetura do implícito. Tese (Doutorado em Linguística). Universidade Federal de Santa Catarina. Florianópolis, 2001.

KOCH, I. V.; MARCUSCHI, L. A. Processos de referenciação na produção discursiva. Disponível em: <www.ceufpe.br/ceel/bibitonio.html>. Acesso em: 22 fev. 2007

Desvendando os segredos do texto. São Paulo: Cortez, 2002.

O texto e a construção dos sentidos. São Paulo: Contexto, 1997.

MARCUSCHI, L. A. Quando a referência é uma inferência. Conferência. São Paulo: GEL/Unesp, 2002.

. Anáfora indireta: O barco textual e suas âncoras. In: KOCH, I. V.; MORATO, E. M.; BENTES, A. C. (Orgs.). Referenciação e discurso. São Paulo: Contexto, 2005.

TRAVAGLIA, L. C. Gramática e interação: uma proposta para o ensino da gramática no 1. ${ }^{\circ}$ e 2. ${ }^{\circ}$ graus. São Paulo: Cortez, 1996.

Recebido para publicação em 09 de junho de 2009. Aceito para publicação em 18 de fevereiro de 2010. 